\title{
Consumer trust in the dairy value chain in China: The role of trustworthiness, the melamine scandal, and the media
}

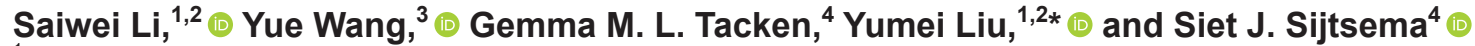 \\ ${ }^{1}$ Beijing Food Safety Policy and Strategy Research Base, China Agricultural University, Haidian District, 100083 Beijing, P. R. China \\ ${ }^{2}$ College of Economics and Management, China Agricultural University, Haidian District, 100083 Beijing, P. R. China \\ ${ }^{3}$ Wageningen University and Research, Animal Production Systems Group, Wageningen $6700 \mathrm{AH}$, the Netherlands \\ ${ }^{4}$ Wageningen University and Research, Wageningen Economic Research, Wageningen $6700 \mathrm{AA}$, the Netherlands
}

\section{ABSTRACT}

This study provides a deep insight into Chinese consumer trust in the Chinese dairy value chain, as a lack of trust due to the 2008 melamine scandal has been widely recognized as a barrier to the development of the domestic dairy industry in China. Based on face-to-face interviews with 954 Chinese consumers in Beijing, Shanghai, and Shijiazhuang, this study measured consumer trust in farmers, manufacturers, retailers, the government, and third parties. Consumer trust was studied by measuring the effect of beliefs on the trustworthiness of actors (i.e., competence, benevolence, integrity, credibility, and openness), and current experiences regarding the melamine scandal and the media. The results showed that the level of trust in dairy chain actors varied. The government and third parties were relatively highly trusted, whereas retailers were considered less trustworthy. The importance of consumer beliefs about trustworthiness are different among actors. Consumer belief of competence determines trust in farmers and manufacturers. For retailers, the government, and third parties, respectively, benevolence, credibility, and openness are the most important factors. Trust in dairy chain actors is still strongly negatively affected by current experiences regarding the melamine scandal, even though it occurred more than 10 years ago. Using social media to directly provide more information and establish continuous daily communication with consumers could help manufacturers and third parties to strengthen consumer trust.

Key words: consumer trust, food safety, dairy value chain, food scandal, media influence

Received October 2, 2020.

Accepted March 15, 2021.

*Corresponding author: ymliu8028@cau.edu.cn

\section{INTRODUCTION}

Trust plays a growing and crucial role in consumer decision-making for food purchases (Coveney, 2008). As a much-cited definition by Rousseau et al. (1998, p. 395) states, trust is defined as a "psychological state comprising the intention to accept vulnerability based upon positive expectations of the intentions or behavior of another." Faced with the increasing complexity of the food supply chain, consumers cannot easily assess credence attributes such as food safety and determine whether the food they purchase meets their expectation (Lassoued and Hobbs, 2014). Trust in the food value chain could compensate for consumers' lack of knowledge of food cultivation and production processes (de Jonge et al., 2007). Consumers place their trust in stakeholders in the food value chain (farmers, manufacturers, and retailers of food supply; regulatory institutions responsible for managing hazards) and rely on them to supply safe food (Lassoued and Hobbs, 2014). Based on maintaining consumer trust, stakeholders have social license to operate with minimal formalized restrictions (Arnot et al., 2016). Once consumer trust is lost, the social license of these stakeholders, especially food suppliers, will be threatened and will be replaced with high-cost, inflexible social control, such as regulation, legislation, or market-based mandates (Arnot et al., 2016).

In China, consumer trust has been recognized as a major concern hindering domestic dairy development (Li and Jiang, 2015). As one of the most notorious food safety issues, the 2008 melamine scandal destroyed Chinese consumer trust in the domestic dairy industry (Lu, 2010). It was reported that 6 infants had died and almost 300,000 children became ill due to consuming infant formula contaminated with melamine, an industrial chemical material for plastics production (Qiao et al., 2012). Subsequently, other dairy scandals relating to illegal additions, such as hydrolyzed proteins in 2009, detergent in 2012, and mercury in 2012 (Wu et 
al., 2018), further exacerbated the trust crisis. More than a decade after the melamine scandal, the Chinese dairy industry has undergone comprehensive reforms, including the promulgation of the Food Safety Law and strict dairy industry regulations, the establishment of independent third-party inspections, improvements in dairy farming scale and standardization, and the adoption of advanced production technology and equipment (Jia et al., 2012; Jiang, 2015).

Although the safety and quality of domestic dairy products has been significantly improved (Dairy Association of China and Ministry of Agriculture and Rural Affairs of China, 2018), deep distrust remains such that consumers show obvious preferences for imported dairy products, especially infant milk formula (Liu et al., 2018). These preferences further hinder the development of the domestic dairy industry, which lacks competitive advantages due to high costs of raw milk production compared with imported dairy brands (Liu et al., 2018). Therefore, a detailed understanding of the current degree of consumer trust in the dairy chain and its determinants are crucial for suppliers and policy makers to develop effective communication strategies.

Trust in food chain actors has been found to be largely determined by consumer beliefs about the trustworthiness of these actors (Macready et al., 2020). Beliefs about trustworthiness are consumers' reasoned assessments of the characteristics of an actor and form the cognitive basis of overall trust in the actor (Macready et al., 2020). The types of beliefs determining trustworthiness are not uniform in the existing literature; competence, care, and openness are recognized as 3 prominent types (de Jonge et al., 2007). Macready et al. (2020) studied 5 countries in Europe, which showed that beliefs in competence and openness exert stronger effects on consumer trust in food chain actors than care does. In a large US survey, Sapp et al. (2009) found perceived competence and fiduciary responsibility of actors accounted for most of the explained variance of trust in the food system. In comparison, by conducting a survey of UK consumers, Yee et al. (2005) distinguished beliefs about trustworthiness in a more detailed manner into competence, credibility, reliability, integrity, benevolence, and providing information, and found that providing information and showing benevolence and integrity to consumers can increase trust in farmers. Most studies of Chinese consumers apply the scale of de Jonge et al. (2007) to measure consumer trust (e.g., Xun, 2011; Gong et al., 2012; Cao, 2019) but few studies identified determining components of trust. Only $\mathrm{Lu}$ (2010) found that consumer beliefs in competence and credibility contributed to consumer trust in manufacturers and government. Jiang (2015) also examined the effects of consumer beliefs about competence and care and found both positively affect consumer trust in farmers, manufactures, retailers, and government. These insights provide some references for quantifying consumer beliefs about trustworthiness but are linked to food production in general; thus, they still need to be adapted and examined in the context of Chinese dairy sector.

The media is also recognized as an important factor in consumer attitudes toward food safety (Kuttschreuter et al., 2014; Mou and Lin, 2014) and consumers trust in food chain actors or the whole food system (Chen, 2013; Henderson et al., 2014; Wilson et al., 2014; Kollat and Farache, 2017). As a key source of food risk information, traditional media, such as television, radio, and newspapers, have a profound influence on consumers' perception of food safety (Houghton et al., 2008). With the substantial changes of communication outlets in recent decades, online media sources (i.e., news websites) have become a key channel to provide consumers with information on diverse topics (Kuttschreuter et al., 2014). Social media is also increasingly being used by consumers to gain information about food (Kuttschreuter et al., 2014), in part due to its 2-way communication format and speed of accessing information (Henderson et al., 2017). Collectively, these different media outlets are believed to play an increasing role in influencing consumer trust, but to our knowledge, no work has looked at disentangling the effects of different media outlets on consumer trust.

Most current studies either focused on measuring Chinese consumer trust in the dairy value chain specifically right after the melamine scare (e.g., Lu et al., 2010; Wang, 2012; Li and Jiang, 2015) or investigated the role of consumer trust in confidence in dairy products (e.g., Lu, 2010; Jiang, 2015; Cao, 2019; Li, et al., 2019a) and consumption behavior (e.g., Wang, 2012; Zhang, 2014). Only a few studies looked into the determinants of consumer trust but mainly focused on a single actor, such as dairy enterprise (e.g., Sun, 2015), or a few actors along the dairy chain ( $\mathrm{Lu}, 2010$; Jiang, 2015). Furthermore, attention still needs to be given to the melamine scandal, which was found not only to decrease consumer trust after the outbreak (Wang, 2012), but to have continuing negative effects on consumer attitudes toward food safety within the dairy supply chain ( $\mathrm{Li}$ et al., 2019b). However, to our knowledge, empirical evidence on the long-term effect of the melamine scandal on current consumer trust in the actors of the Chinese dairy chain is still lacking.

Therefore, the first aim is to explore the trust level of Chinese consumers in the Chinese dairy value chain. The second aim is to analyze how current experiences arising from the 2008 melamine scandal, beliefs about trustworthiness, and different media outlets affect con- 
Table 1. Annual income per capital, population, and gross domestic product (GDP) per capita of Beijing, Shanghai, and Shijiazhuang ${ }^{1}$

\begin{tabular}{|c|c|c|c|c|c|}
\hline Region & Area & Sample & $\begin{array}{c}\text { Annual income } \\
\text { per capita (USD) }\end{array}$ & $\begin{array}{l}\text { Population } \\
\text { (million) }\end{array}$ & $\begin{array}{c}\text { GDP per } \\
\text { capita (USD) }\end{array}$ \\
\hline \multirow[t]{3}{*}{ Beijing } & City district & 186 & $11,117.94$ & & \\
\hline & County & 73 & 8.375 .61 & & \\
\hline & Whole region & 324 & $8,867.70$ & 21.54 & $24,043.93$ \\
\hline \multirow[t]{2}{*}{ Shanghai } & City district & 182 & $9,941.80$ & & \\
\hline & County & 67 & $9,007.13$ & & \\
\hline \multirow{4}{*}{ Shijiazhuang } & City district & 183 & $6,859.13$ & & \\
\hline & County & 68 & $4,236.84$ & & \\
\hline & Village & 67 & $2,288.94$ & & \\
\hline & Whole region & 318 & $5,335.50$ & 10.39 & $7,739.24$ \\
\hline
\end{tabular}

${ }^{1}$ The exchange rate $\$ 1$ USD $=6.83$ yuan (accessed on September 25, 2020).

${ }^{2}$ Data were calculated based on survey data. In the survey, we provided 8 options of different levels of family income per month. Respondents were asked to choose the option of the total income of their family and answer the number of family members in their household. Then, we calculated the annual income per capita.

${ }^{3}$ Data were accessed from National Bureau of Statistics (2020) and Shijiazhuang Municipal Bureau of Statistics (2020).

sumer trust in the dairy value chain. This study also considers the differences in trust between consumer groups with different demographic characteristics, such as age and education, which are highly related to consumer trust in the food chain (Frewer et al., 1998; Henderson et al., 2011). In this study, we define consumers as the persons who purchase dairy products and are motivated by both private and public concerns. Namely, they combine the private role of consumers with the public role as citizens. This study contributes to the research by including 5 main actors, including farmers, manufacturers, retailers, the government, and third parties, to build a picture of current Chinese consumer trust in the Chinese dairy value chain. Meanwhile, 5 types of beliefs about trustworthiness (competence, benevolence, integrity, credibility, openness) are included to approach a deeper understanding of consumer evaluation on dairy chain actors. Moreover, we distinguished the effects of 3 media sources (traditional, social, and online media) on consumer trust. These results will be instrumental in helping dairy chain stakeholders enhance consumer trust and promote the development of the Chinese dairy sector.

\section{MATERIALS AND METHODS}

\section{Data Collection and Sampling}

The empirical analysis for this study is based on data from dairy consumers in 3 regions: Beijing, Shanghai, and Shijiazhuang, including their cities, surrounding suburbs, and rural areas. Beijing is the capital city and the political center of China, and Shanghai is a global financial center. Both are the most developed regions in China, with a large consumer base, located in the north and east of the Chinese mainland, respectively. Shijiazhuang is the provincial capital of the Hebei province in the north of China, which had the highest milk output nationwide in 2019 (Sina News, 2020). Also, it was the starting point of the 2008 melamine scandal (Sohu News, 2009), rendering it a suitable area to study consumer trust. The economic development and population of the 3 regions are shown in Table 1.

Data were collected via a cross-sectional survey based on stratified multistage sampling to ensure the representativeness of the sample. A cross-sectional survey means that the survey collects data to make inferences about a population of interest (universe) at 1 point in time. First, a sampling frame was created at the district level; 2 city districts from each of 3 regions were randomly selected, and 2 supermarkets from each of 6 districts were randomly selected. Then 50 consumer respondents were randomly selected from each of 12 supermarkets. The second step of the sampling process consisted of randomly selecting one county from each of 3 regions, 2 supermarkets from each of 3 counties, and 35 consumer respondents from each of 6 supermarkets. All surveyed supermarkets were randomly selected from the list of the top 10 supermarkets on a popular Chinese review website (http://www.dianping.com/). In the last step, 2 stratified random samples of villages were chosen from each of 3 selected counties, and 35 consumer respondents were randomly selected from the groceries in each of 6 villages. This approach identified 3 cities, 6 districts, 12 supermarkets, and 600 urban consumers; 3 counties, 6 supermarkets, and 210 suburban consumers; and 6 villages and 210 rural consumers.

The formal survey was conducted from July to August 2018. A total of 1,020 consumer responses were recorded. After excluding incomplete responses, 954 
Table 2. Measurement items of consumer beliefs about trustworthiness regarding dairy safety

\begin{tabular}{lll}
\hline $\begin{array}{l}\text { Trustworthiness } \\
\text { belief }\end{array}$ & Item & Reference \\
\hline $\begin{array}{l}\text { Competence } \\
\begin{array}{l}\text { Benevolence } \\
\text { Integrity }\end{array}\end{array}$ & Are capable enough to deal with dairy safety issues & de Jonge et al. (2007) \\
Credibility & Act in the consumers' interest and concern about their health & Yee et al. (2005) \\
Openness & Would not knowingly do anything to hurt consumers & Yee et al. (2005) \\
\hline
\end{tabular}

valid questionnaires were recorded in the final analysis. Consumer respondents who were $18 \mathrm{yr}$ old or older were interviewed face-to-face by trained students from the universities of 3 regions. Respondents were interviewed only if they were responsible for purchasing food for their household and had purchased dairy products for themselves or their family members.

Before the formal survey, a pilot study was conducted in Beijing in June 2018 to evaluate the clarity and accuracy of the questions and the overall flow of the designed questionnaire. Four shopping malls were randomly selected from 6 districts in Beijing as the survey sites, and a total of 100 respondents (43 women and 57 men) were met at integer hour points. Respondents were interviewed face-to-face by 10 trained students from China Agricultural University. Based on their responses, we improved the questionnaires, such as by explaining professional terms and simplifying complex questions, which made the questionnaires easier to understand.

\section{Questionnaire Development}

The questionnaire contains measurement scales on overall trust in actors, beliefs about the trustworthiness of actors, current experiences regarding the melamine scandal, the media, and consumer characteristics.

Overall Trust in Actors Regarding Dairy Safe$t y$. The key subject of the study focuses on consumer trust in the chain actors, farmers, manufacturers, retailers, the government, and third parties, as they are the main actors involved in dairy production, processing, distribution, regulation, and independent inspection. Following Macready et al. (2020), consumers' overall trust in each actor was measured by asking respondents, "to what extent do you trust this actor when considering dairy safety," and scoring the question on a 5 -point scale $(1=$ strongly distrust to $5=$ strongly trust).

Beliefs About the Trustworthiness of Actors. Five measurement items regarding the beliefs about trustworthiness were designed to measure how consumers evaluate the competence, benevolence, integrity, credibility, and openness of the main dairy actors regarding dairy safety (Table 2). All the corresponding measurements are based on the previous work on trust (Poortinga and Pidgeon, 2003; Yee et al., 2005; de Jonge et al., 2007). Respondents were asked how much they agreed with these items for each actor and scored from $1=$ strongly disagree to $5=$ strongly agree.

Current Experiences Regarding the Melamine Scandal. It is expected that the 2008 melamine scandal still has an influence on consumer trust. To measure this, respondents were asked to what extent they agreed with the statement, "the 2008 melamine scandal still affects my consumption behavior of dairy today," ranging from $1=$ strongly disagree to $5=$ strongly agree.

Media. The information sources were distinguished into 3 types, including traditional media, online media, and social media, to examine the influence of each on consumer trust. Traditional media is defined as nondigital media channels (e.g., television and radio). Online media refers to the media that can be viewed, distributed, or stored on digital electronic devices. To distinguish that from social media, online media in this study is specified as the media using the Internet to present or exchange information, such as search engines or news websites. Social media here is defined as "a group of Internet-based applications that build on the ideological and technological foundations of web 2.0, and that allow the creation and exchange of user generated content" (Kaplan and Haenlein, 2010, p 61; e.g., Facebook, YouTube, Weibo). Respondents were asked, "how often do you refer to the information provided by traditional (or social, online) media when making consumption choices of dairy products?" with a 5-point response scale from $1=$ never to $5=$ usually.

Consumer Characteristics. Gender, age, education, income, knowledge about dairy safety, and place of residence were studied to explore the heterogeneity in consumer trust. Specifically, knowledge about dairy safety was measured by asking respondents, "how much do you know about quality and safety of dairy products," ranging from $1=$ not know at all to $5=$ very much. As for the city of residence, 3 cities, Shijiazhuang, Beijing, and Shanghai, are included. 


\section{Data Analysis}

Empirical analysis was conducted with STATA/SE 16 (Stata Corp.). Kruskal-Wallis one-way ANOVA test was applied to analyze the differences in consumers' overall trust between the 5 dairy actors and beliefs about trustworthiness between consumer groups with different characteristics. Then, the ordered logit model was used to examine determinants of consumers' overall trust in each actor of the dairy value chain. This model can "recognize variable ordinality, avoid arbitrary assumptions about scale, and allow for the analysis of continuous, dichotomous, and ordinal variables" (Winship and Mare, 1984, p. 512). Therefore, it is appropriate in this study to estimate consumer trust with a meaningful sequential order ranging from 1 (strongly distrust) to 5 (strongly trust). The independent variables include consumer beliefs about trustworthiness of actors, current experiences regarding the melamine scandal, the media, and consumer characteristics. Shijiazhuang is the outbreak location of the melamine scandal; thus, it was treated as the benchmark group for consumers residing in Beijing and Shanghai in the model. To measure the effects of each factor on consumers' overall trust, the odds ratios ( OR) were estimated by measuring the changes in probability of the dependent variable following a unit change in the independent variable. When the OR is equal to 1 , the effect of the unit variation of the factor on the dependent variable is null. When keeping the values of other factors constant, the larger the deviation is from the unit value, the greater the effect of the factor on the dependent variable.

\section{RESULTS}

\section{Consumer Characteristics}

The sociodemographic characteristics of the respondents are summarized in Table 3. The majority of the respondents were women $(62.26 \%)$. More than half of respondents were between 26 and $55 \mathrm{yr}$ of age. The education and income levels of respondents were relatively high. Nearly $70 \%$ of respondents had high school or above as their highest education level, with respondents who had college or university $(41.82 \%)$ as their highest education level in the majority. About $30 \%$ of respondents had children younger than $12 \mathrm{yr}$ old in their household. Most participants had monthly incomes greater than the national average of \$366 USD. The main reason for the relatively high education and income level is that the survey was conducted in 3 relatively developed cities in China, where many people are well educated. More than half of the respondents spend $\$ 14.64$ to $\$ 58.57 / \mathrm{mo}$ on dairy consumption. In
Table 3. Characteristics of respondents $(\mathrm{n}=954)$ interviewed in a study on consumer trust in the dairy value chain in 3 regions of China

\begin{tabular}{|c|c|c|}
\hline Characteristic & $\begin{array}{l}\text { No. of } \\
\text { respondents }\end{array}$ & Percent \\
\hline \multicolumn{3}{|l|}{ Gender } \\
\hline Female & 594 & 62.26 \\
\hline Male & 360 & 37.74 \\
\hline \multicolumn{3}{|l|}{ Age (yr) } \\
\hline $18-25$ & 253 & 26.52 \\
\hline $26-35$ & 216 & 22.64 \\
\hline $36-45$ & 170 & 17.82 \\
\hline $46-55$ & 134 & 14.05 \\
\hline$\geq 56$ & 181 & 18.97 \\
\hline \multicolumn{3}{|l|}{ Ēducation } \\
\hline Elementary school & 83 & 8.70 \\
\hline Junior high school & 213 & 22.33 \\
\hline High school & 206 & 21.59 \\
\hline College/university & 399 & 41.82 \\
\hline Graduate studies & 53 & 5.56 \\
\hline \multicolumn{3}{|l|}{ Children in household $^{2}$} \\
\hline No & 673 & 70.55 \\
\hline Yes & 281 & 29.45 \\
\hline \multicolumn{3}{|l|}{ Income $^{3}$} \\
\hline Low income $(\leq \$ 366)$ & 423 & 44.34 \\
\hline High income $(>\$ 366)$ & 531 & 55.66 \\
\hline \multicolumn{3}{|c|}{ Dairy expense per month ${ }^{4}$} \\
\hline$<\$ 14.64$ & 295 & 30.92 \\
\hline$\$ 14.64-\$ 58.57$ & 510 & 53.46 \\
\hline$>\$ 58.57$ & 149 & 15.62 \\
\hline \multicolumn{3}{|c|}{ Knowledge about dairy safety } \\
\hline Not know at all & 16 & 1.68 \\
\hline A little bit & 235 & 24.63 \\
\hline Some & 407 & 42.66 \\
\hline A lot & 285 & 29.77 \\
\hline Very much & 12 & 1.26 \\
\hline \multicolumn{3}{|l|}{ Region residence } \\
\hline Beijing & 324 & 33.96 \\
\hline Shanghai & 312 & 32.70 \\
\hline Shijiazhuang & 318 & 33.33 \\
\hline
\end{tabular}

${ }^{1}$ Number of samples.

${ }^{2}$ Children younger than 12 yr old in household.

${ }^{3}$ The per capita monthly disposable income of residents in 2018 and 2019 are 2,352 yuan and 2,561 yuan respectively (National Bureau of Statistics, 2020). Thus, 2,500-yuan per capita monthly income was used as the cut-off point to distinguish consumers into groups of low and high income. According to exchange rate $\$ 1 \mathrm{USD}=6.83$ yuan (accessed on September 25, 2020), $\$ 366$ USD $=2,500$ yuan.

${ }^{4}$ According to exchange rate $\$ 1 \mathrm{USD}=6.83$ yuan, $\$ 14.64 \mathrm{USD}=100$ yuan, $\$ 58.57$ USD $=400$ yuan.

general, respondents expressed that they had a certain understanding of the safety of dairy products, where more than $70 \%$ of respondents perceived themselves as knowing some or much about dairy safety. Respondents were almost evenly distributed among 3 cities.

\section{Overall Trust in Dairy Value Chain Actors}

Distribution of Likert scale scores and mean values of overall trust in 5 dairy chain actors are shown in Figure 1 and Table 4. The results indicate mediumhigh trust levels in all actors, with mean values slightly above the midpoint of the scale. There were differences 
Table 4. Mean (SD) scores of overall trust in dairy value chain actors among all respondents and respondent groups with different characteristics in the Beijing, Shanghai, and Shijiazhuang regions of China ${ }^{1}$

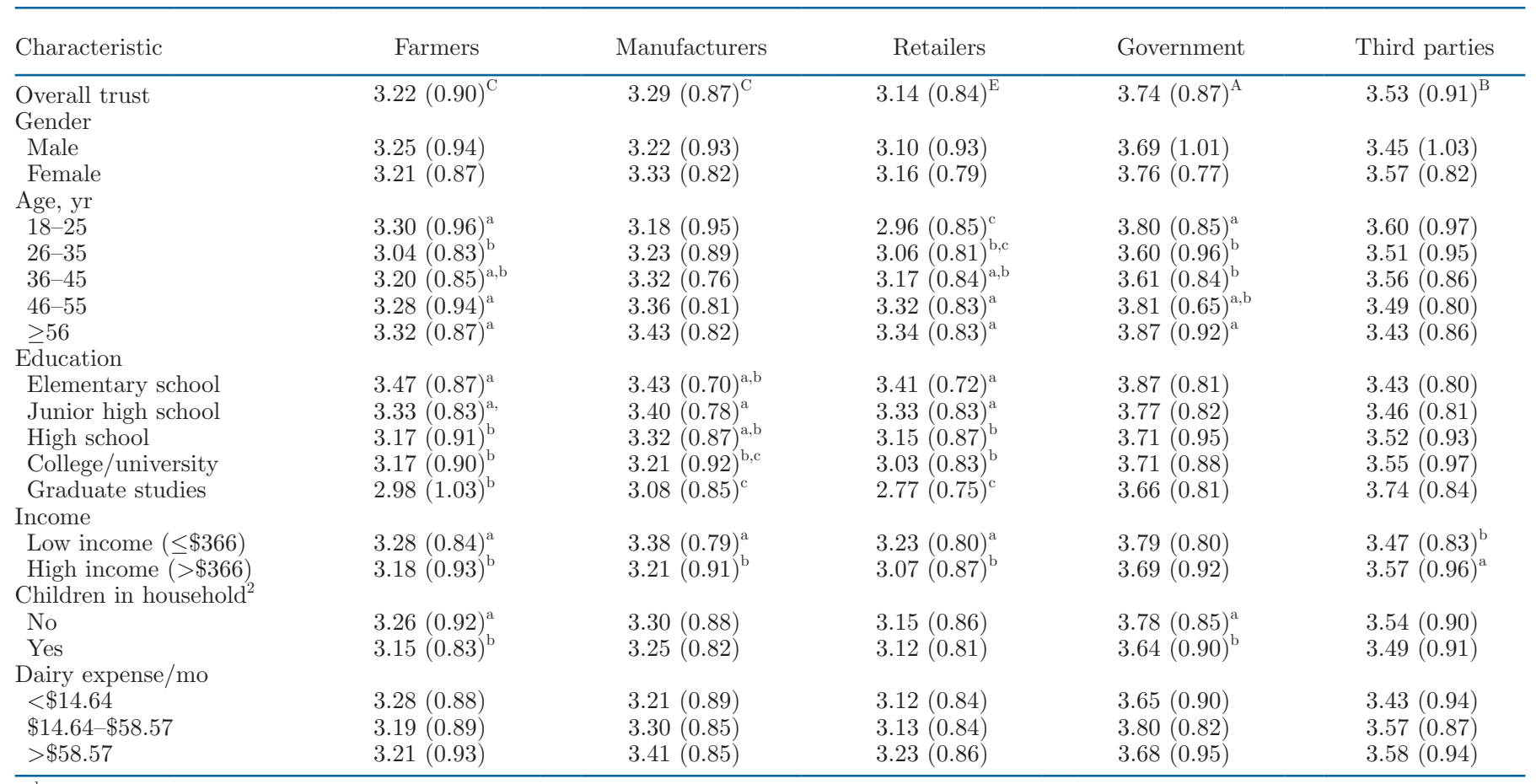

${ }^{\mathrm{a}-\mathrm{d}}$ Different letters within columns for different characteristic consumer groups indicate significant differences in trust among consumer groups $(P<0.05)$.

${ }^{\mathrm{A}-\mathrm{D}}$ Different letters within rows indicate significant differences in overall trust in different actors $(P<0.05)$.

${ }^{1}$ The overall trust levels for 5 dairy actors were scored with a five-point Likert scale $(1=$ strongly disagree, $2=$ disagree, $3=$ unsure, $4=$ agree, $5=$ strongly agree).

${ }^{2}$ Children younger than 12 yr old in household.

in the overall trust between the 5 actors $(P<0.001)$. Consumers trust government and third parties more than other dairy chain actors. Among them, the highest mean score (SD) was for trust in the government with 3.74 (0.87), followed by third parties with 3.53 (0.91), whereas the mean value of trust in retailers was the lowest with 3.14 (0.84).
Table 4 also shows that the overall trust in the 5 actors significantly varies across consumer groups with different ages, education, income levels, and consumers who have children or not (all $P<0.05$ ). First, elderly respondents trusted farmers, retailers, and the government more than younger ones did. Second, for farmers, manufacturers, and retailers, the mean trust

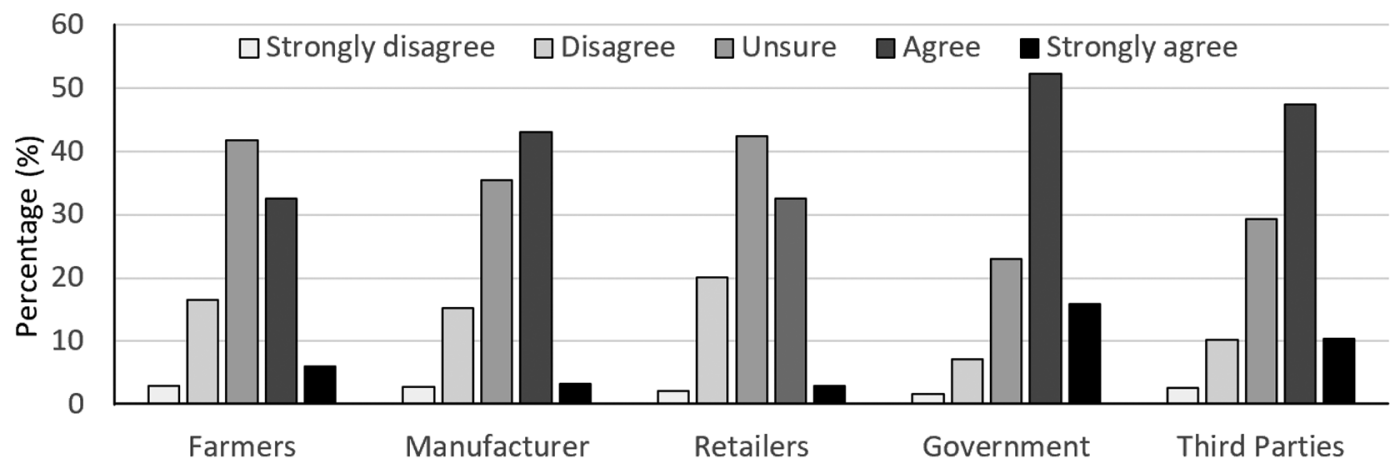

Figure 1. Distribution of consumers' Likert scale responses to overall trust in 5 dairy chain actors in 3 regions of China. 
levels of respondents who had an education level above high school were significantly lower than those with elementary or junior high school education levels. Third, respondents with low income trusted more in farmers, manufacturers, and retailers but less in third parties compared with those with high income. Fourth, respondents without children in their household trusted farmers and the government more than those with children.

\section{Beliefs About the Trustworthiness of Dairy Value Chain Actors}

Table 5 shows the mean values for consumer beliefs about the trustworthiness of each dairy actor. Respondents rated the trustworthiness highest for government, followed by third parties, but rated farmers and retailers relatively lower, which mirrored the differences in overall trust of dairy actors. Furthermore, respondents also rated each actor significantly differently on different aspects of trustworthiness. The results showed that consumers rated the credibility and openness of farmers, manufacturers, government, and third parties relatively lower than other beliefs. Differently, retailers were rated relatively low for their competence and credibility compared with other beliefs of trustworthiness.

\section{Influencing Factors of Consumer Trust in Each Actor}

Five ordered logit models were conducted with overall trust in each dairy value chain actor as dependent variables. Beliefs in the trustworthiness of each actor, current experiences regarding the melamine scandal, media, and consumer characteristics were entered as the predictors in the models. The model results are presented in Table 6. Inspection of the coefficients of the models showed that beliefs in trustworthiness accounted for the bulk of the explanation of variance, but the importance of different trustworthiness beliefs varied across actors.
Competence and benevolence were the 2 most important trustworthiness beliefs that were significantly positively related to consumers' overall trust of farmers, manufacturers, and retailers (all $P<0.01$ ). For farmers and manufacturers, belief in competence exerted the strongest effect on trust. For every one unit increase in consumer valuation on competence, the odds of consumers having more trust in farmers and manufacturers increased 158 and 140\%, respectively. The higher consumers evaluate farmer and manufacturer competence in controlling the quality and safety during raw milk production and dairy processing, the more they trust them. For retailers, belief in benevolence had the strongest effect on consumer trust. For every one unit increase in consumer valuation on benevolence, the odds of consumers having more trust in retailers increased $170 \%$. The results show that consumers are more likely to trust the retailers providing dairy products of good quality when they perceive that retailers care about the consumer's interest and welfare.

In contrast with the dairy supply actors, belief in credibility was the strongest predictor of consumer trust in government. The odds of consumers having more trust in government increase $111 \%$ for every one unit increase in consumers' valuation on credibility. Consumers who believe the government does not distort facts for their own benefit regarding dairy safety, tend to trust the government. As for third parties, belief in openness played the most important role in increasing consumer trust. The odds of consumers having more trust in third parties increase $100 \%$ for every one unit increase in consumer valuation on openness. The more consumers perceive that third parties can disclose information related to dairy safety, the more they trust third parties. In addition, belief in competence was found to be positively related to consumer trust in government and retailers.

Current experiences regarding the 2008 melamine scandal had significant negative effects on consumer

Table 5. Mean scores (SD) of consumer beliefs about the trustworthiness of dairy value chain actors in the Beijing, Shanghai, and Shijiazhuang regions of China ${ }^{1}$

\begin{tabular}{|c|c|c|c|c|c|}
\hline $\begin{array}{l}\text { Trustworthiness } \\
\text { belief }\end{array}$ & Farmers & Manufacturers & Retailers & Government & Third parties \\
\hline $\begin{array}{l}\text { Competence } \\
\text { Benevolence } \\
\text { Integrity } \\
\text { Credibility } \\
\text { Openness }\end{array}$ & $\begin{array}{l}3.32(0.84)^{\mathrm{a}, \mathrm{D}} \\
3.24(0.83)^{\mathrm{b}, \mathrm{D}} \\
3.35(0.84)^{\mathrm{a}, \mathrm{D}} \\
3.17(0.82)^{\mathrm{c}, \mathrm{D}} \\
3.16(0.83)^{\mathrm{c}, \mathrm{D}}\end{array}$ & $\begin{array}{l}3.49(0.74)^{\mathrm{a}, \mathrm{C}} \\
3.43(0.74)^{\mathrm{b}, \mathrm{C}} \\
3.43(0.77)^{\mathrm{b}, \mathrm{C}} \\
3.28(0.81)^{\mathrm{c}, \mathrm{C}} \\
3.31(0.76)^{\mathrm{c}, \mathrm{C}}\end{array}$ & $\begin{array}{l}3.21(0.82)^{\mathrm{c}, \mathrm{E}} \\
3.24(0.79)^{\mathrm{bc}, \mathrm{D}} \\
3.33(0.78)^{\mathrm{a}, \mathrm{D}} \\
3.20(0.80)^{\mathrm{c}, \mathrm{D}} \\
3.30(0.77)^{\mathrm{ab}, \mathrm{C}}\end{array}$ & $\begin{array}{l}3.81(0.78)^{\mathrm{a}, \mathrm{A}} \\
3.84(0.76)^{\mathrm{a}, \mathrm{A}} \\
3.86(0.75)^{\mathrm{a}, \mathrm{A}} \\
3.74(0.83)^{\mathrm{b}, \mathrm{A}} \\
3.72(0.82)^{\mathrm{b}, \mathrm{A}}\end{array}$ & $\begin{array}{l}3.65(0.75)^{\mathrm{a}, \mathrm{B}} \\
3.55(0.80)^{\mathrm{bc}, \mathrm{B}} \\
3.56(0.77)^{\mathrm{b}, \mathrm{B}} \\
3.46(0.83)^{\mathrm{d}, \mathrm{B}} \\
3.49(0.82)^{\mathrm{cd}, \mathrm{B}}\end{array}$ \\
\hline
\end{tabular}




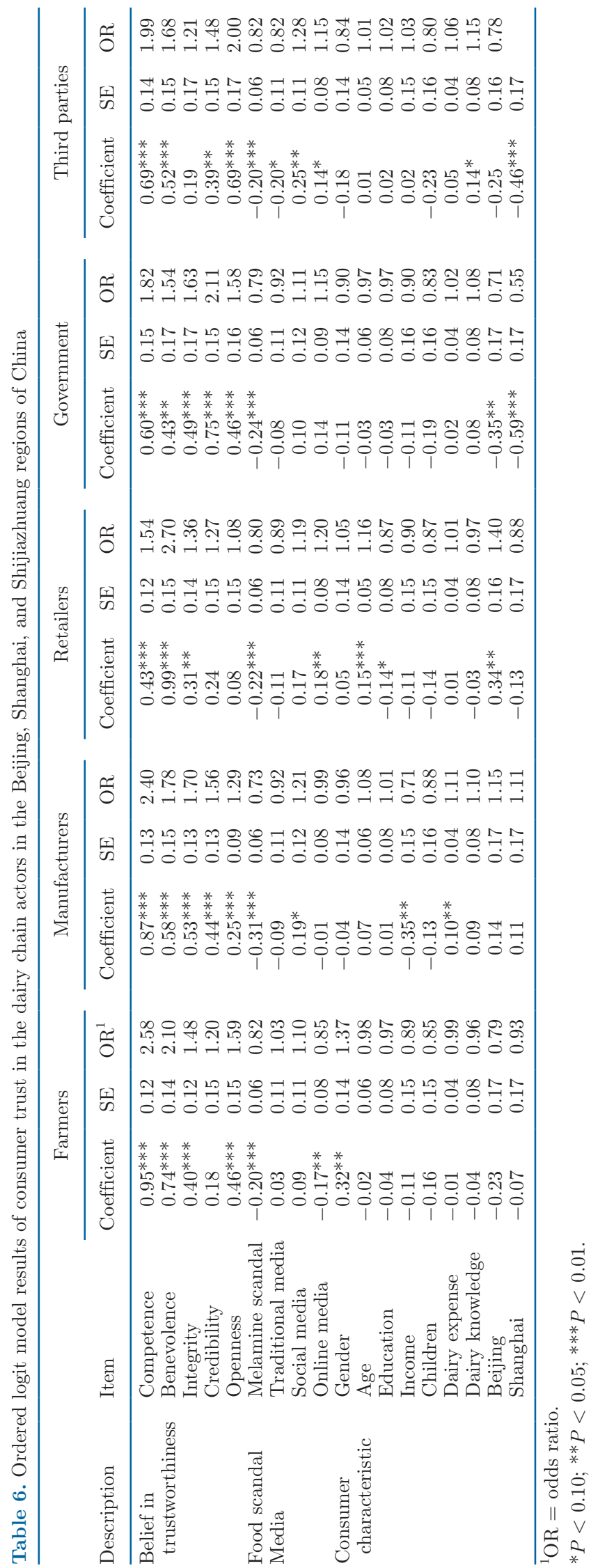

trust in all dairy chain actors (all $P<0.01$ ). For all dairy chain actors, the odds of consumers having more trust decrease between 18 and $27 \%$ for every one unit increase in the experiences regarding the melamine scandal. This indicates that this severe food scandal still plays a role in decreasing consumer trust in all actors along the dairy value chain, although it occurred more than 10 yr ago.

The positive role of social media was found for consumer trust in manufacturers and third parties. For every unit increase in frequency of using social media as information sources, the odds of consumers having more trust in manufacturers and third parties increase 21 and $28 \%$, respectively. Consumers who preferentially used social media to gather information were more likely to trust manufacturers and in particular, third parties. Interestingly, in the case of third parties, participants that used traditional media as sources of information were less likely to trust. Moreover, the results show the opposite effect of online media on consumer trust in farmers compared with retailers and third parties. When consumers' dairy-related information is accessed more from online media, they are more likely to trust farmers less, but trust retailers and the third parties more.

Consumers' overall trust in farmers, manufacturers, and retailers was found to be affected by consumer characteristics. First, male consumers trust farmers more than female consumers. The odds of male consumers trusting farmers more are 1.37 times the odds of women. Second, elder consumers are more likely to trust retailers than younger consumers. With a 1-yr increase in age, the odds of elder consumers trusting retailers more are 1.16 times the odds of younger consumers. Third, education had a negative relationship with consumer trust in retailers. The odds of consumers with higher education trusting retailers more are only 0.87 times the odds of consumers with lower education. Fourth, the level of income was negatively related to trust in manufacturers. The odds of consumers with higher income having more trust in manufacturers are only 0.71 times the odds of consumers with lower income. Fifth, consumers who spend more money on dairy consumption per month are more likely to trust manufacturers. The odds of consumers with higher dairy expenses trusting more in manufacturers are 1.11 times the odds of consumers with the lower dairy expense. In addition, after controlling all the above potential factors, differences in consumer trust in retailers, the government, and third parties remained among the 3 cities. Beijing consumers trusted retailers more but trusted the government less than consumers in Shijiazhuang. Shanghai consumers trusted the government and third parties less than those in Shijiazhuang. 


\section{DISCUSSION}

The goal of this study was to get a further understanding of Chinese consumer trust in the dairy value chain. Using data collected via a cross-sectional survey in 3 Chinese cities, this study comprehensively measured and compared the overall trust in farmers, manufacturers, retailers, the government, and third parties. Based on that, this study further investigated how beliefs in trustworthiness (including competence, benevolence, integrity, credibility, and openness), current experiences regarding the melamine scandal, the media, and consumer characteristics affect consumer trust in each actor, by applying the ordered logit model.

In general, Chinese consumers displayed a mediumhigh level of trust in the 5 dairy chain actors. Compared with the previous studies (Lu et al., 2010; Li and Jiang, 2015), it was found that the trust level of all the 5 actors had increased, especially for the government. Furthermore, the results show that differences in consumer trust existed among the 5 actors. In general, Chinese consumers had the highest level of trust in government, then third parties, whereas the lowest scores were in retailers, then farmers. Different results were observed by such studies in other countries. For example, Macready et al. (2020) found that consumers from 5 countries in Europe tended to trust farmers and retailers more than government and manufacturers in the food chain. Ariyawardana et al., (2017) found Australian consumers trusted vegetable growers and government more than vegetable processors and retailers. Chinese consumers' valuation on the trustworthiness could explain the differences among 5 dairy chain actors to some extent. The government and third parties enjoyed relatively high levels of trust and received higher opinions on trustworthiness. This is consistent with previous Chinese studies (Qiu et al., 2012; Chen, 2013; Li and Jiang, 2015; Li et al., 2019a), indicating an awareness and appreciation of food regulation and inspection. In comparison, farmers, manufacturers, and retailers were rated lower on the 5 aspects of trustworthiness, especially on credibility and openness. This is similar to Li and Jiang (2015) who found that Chinese consumers are more suspicious about their credibility; for example, they worry that farmers will add harmful substances to raw milk, consider the advertisements of manufacturers as false, or think that retailers will sell expired products. This is the same line of reasoning as Chen (2013), who found that Chinese consumers have the perception that farmers and food manufacturers are the least concerned about the safety and health of food and are not honest about food safety. A possible explanation for consumers distrust of dairy supply actors is that the market-competitive nature of the food supply led to a consumer's general belief that they are purely vested in profit-making (Coveney, 2008). Driven by profit, dairy supply actors might take various measures to promote products and pursue their own profit, such as applying improper food labeling, which might infringe on the interests of consumers and decrease consumer trust (Li and Jiang, 2015). Meanwhile, serious information asymmetry exists between consumers and products along the prolonged supply chain ( $\mathrm{Yu}$ et al., 2018), so that consumers find it hard to access enough information regarding food production and processing. Our finding that nearly $70 \%$ of consumers knew some or do not know about dairy safety at all, also shows consumers' lack of sufficient information, which might lead to difficulty in trusting dairy chain actors. Moreover, the lower trust level for farmers and manufacturers might also be associated with their dishonest production behavior, resulting in dairy scares and the related negative media coverage. As suggested by Dolgopolova et al. (2015), institutions such as food manufacturers who have been linked to previous food safety scandals will be viewed as untrustworthy. Specifically, the lowest level of trust in retailers is worth noting. The way retailers handle food plays a role in influencing dairy safety and consumer trust (Coveney, 2008). Indiscriminate storage and improper treatment of dairy products are common in supermarket and convenience stores in China [e.g., storing yogurt in a refrigerator that cannot guarantee the required temperature, intermittently cutting off the refrigerator power (Zhang et al., 2018), or selling expired dairy products (Sun and Wen, 2016)], which could explain consumer distrust in retailers to some extent. Moreover, retailers are the actors that most frequently have contact with consumers. When food scares occur, most retailers simply return the foods for a refund, or even shirk responsibility, and seldom make more efforts to control food safety (Jiang, 2015), which might be another reason for consumer distrust in retailers.

Based on the results of the ordered logit model, we found that consumer trust in the 5 dairy actors was largely determined by their beliefs about the trustworthiness of these actors, which is in line with previous studies (Yee et al., 2005; Sapp et al., 2009; Arnot, et al., 2016; Macready et al., 2020). The difference is that the effect of beliefs about the 5 trustworthiness factors vary across the dairy actors. When it comes to strengthening overall trust in farmers and manufacturers, consumers' evaluation of the competence of these actors was the most important. One possible reason is that, as actors engaged in producing raw milk and processing dairy products, respectively, the competence of farmers and manufacturers directly determines whether the quality of dairy products can satisfy consumer demand (Afzal 
et al., 2010). Consumer beliefs about benevolence, credibility, and openness were the strongest drivers of trust in retailers, government, and third parties, respectively. First, showing benevolence when providing information about the food system can have a significant effect on consumer trust (Yee et al., 2005; Wilson et al., 2017). Our results are similar to de Jonge et al. (2008) who also found caring for consumer interests is the most important trustworthiness belief for food retailers. Second, the perceived credibility of the government is crucial for consumer trust in governments. As Lobb (2005) pointed out, government agencies have a dual role of risk regulator and risk generator, which can erode the public's trust in government. It means that the government needs enough credibility to take the responsibility of risk regulator during the food safety regulatory process, which could increase consumer trust. Third, transparency has been identified as a crucial strategy for building consumer trust, especially when responding to food scandals (Wilson et al., 2017). Papadopoulos et al. (2012) found that the public has increased desire for scientifically transparent communication from a trusted source and increased access to inspection results. The importance of transparency of third parties might result from the unfamiliarity of this emerging inspection actor among consumers. Thus, increasing transparency could help consumers obtain dairy inspection information, understand the functions of third parties in dairy safety governance, and further increase consumer trust. These results suggest that, for each actor taking its specialized role in the dairy value chain, consumers value different characteristics for different actors. Thus, our results are of great practical significance for every actor to formulate communication strategies by improving their own specially important trustworthiness factor.

As expected, consumers' overall trust in all dairy value chain actors were still strongly negatively affected by current experiences regarding the melamine scandal. This result confirms that food scandals are key events challenging consumer trust in the food value chain (Coveney, 2008; Henderson, et al., 2011) and could greatly diminish public confidence and alter the social license of the food system (Arnot et al., 2016). Compared with previous studies on Chinese consumer trust shortly after the outbreak of the melamine scandal ( $\mathrm{Lu}$ et al., 2010; Wang, 2012; Li and Jiang, 2015), our results further suggest the negative effect of the melamine scandal is profound and lasting on the recovery of consumer trust in the domestic dairy value chain. Interestingly, although Shijiazhuang is the "ground zero" of the melamine scandal, consumers in Shijiazhuang tend to trust more in government and third parties compared with consumers in Beijing and Shanghai. Compared with Beijing and Shanghai, the development of the dairy industry in Shijiazhuang is at the forefront of the province and even the country (Shijiazhuang News Net, 2019). The government attaches great importance to the development of the dairy industry and issued a series of policies, such as the Shijiazhuang Dairy Industry Revitalization Implementation Plan, and measures including promoting the construction of highquality milk source bases, strengthening the quality and safety supervision of fresh milk, and reshaping the image of Shijiazhuang dairy (Shijiazhuang News Net, 2019). As a local company in Shijiazhuang, Junlebao is a well-known dairy company in the country, and its sales revenue in 2018 ranked fourth in the country (Shijiazhuang News Net, 2019). Thus, consumers living in Shijiazhuang who might be more concerned about dairy safety due to the melamine scandal are more likely to see more evidence of monitoring and auditing of the food supply by governments, which might have a positive effect on their trust (Coveney, 2008).

Our results show that social media could play a positive role in strengthening consumer trust, consistent with Kollat and Farache (2017). Mou and Lin (2014) also stated that the use of Weibo (commonly used social media platform in China) contributed to cognitive and behavioral responses to food safety concerns, whereas other online and offline information outlets were largely irrelevant. Consumers who are inclined to use social media tend to treat social media as part of a broader configuration of channel use to seek additional food information, and confirm the official messages sent out by more traditional or online media (Kuttschreuter et al., 2014). Therefore, looking for more dairy information from social media could reduce misunderstandings on complex media information and anxiety due to information asymmetry ( $\mathrm{Xu}, 2020)$, and is proven to be especially important for increasing consumer trust in manufacturers and third parties. However, it is worth noting that social media is also a double-edged sword (Lee, 2015). Peng et al. (2015) found that food safety scandals revealed by social media in China could easily be noticed by consumers, which can trigger large-scale dissemination and awareness among the public and further affect their judgments of expected utility and purchasing behavior. Moreover, we noticed the different roles of online media for retailers and farmers. Compared with traditional media, online media is relatively free and flexible in disclosing food safety risks in China (Yang, 2013; Peng et al., 2015; Liu and Ma, 2016). Unlike retailers, who could provide information on their own websites, farmers have limited channels, and information about them is mostly reported indirectly by mass media. Thus, more unverified information or even rumors about raw milk production are likely to be 
online, which might lead to less consumer trust in farmers. These results further address that the dairy chain actors should be aware of the implications of different types of media communication with consumers.

Finally, we also found that heterogeneity existed in consumer's trust in dairy supply chain actors. Male consumers had more trust in farmers compared with female ones. It is commonly believed that women are more risk averse than men (Wik et al., 2004). Thus, female consumers are more likely to have concerns about threats to their families, such as food risks, and tend to distrust farmers. Different from Wilson et al. (2014), our results showed elderly consumers trusted more in retailers. Richer and better-educated consumers tend to distrust in manufacturers and retailers, respectively. One possible explanation is that such consumer groups might have higher requirements of the dairy products. If the situation in reality fails to meet their previous expectations, then they are likely to be disappointed with the corresponding actors; the gap therefore results in lower trust (Jiang and Liu, 2016). Furthermore, richer consumers can afford to purchase imported dairy products of high quality, and they are more likely to distrust the domestic dairy value chain compared with poorer consumers with limited choices. Another potential reason is that those people tend to pay more attention to dairy safety and are more sensitive about the related negative food scandals, which impairs their trust (Wang and Fan, 2013). Last, it is also found that consumers with higher dairy expenses trust more in manufacturers. Higher dairy expenses indicate to some extent more dairy purchase experiences, which can play a positive role in quality perception, future purchase (Grunert, 2002), and brand loyalty (Ramaseshan and Stein, 2014). Therefore, consumers with higher dairy expense might gain more dairy purchase experiences, which positively increase their satisfaction and trust in manufacturers.

The above results indicate several implications from consumer views on how to build consumer trust in the dairy value chain. First, the dairy chain should pay more attention to establishing credible images to consumers and improve information transparency to promote consumer understanding of the increasingly complex dairy chain. For example, dairy chain actors should collaborate and act and respond in a consistent and transparent way, which is important to ensure consumer trust (Wilson et al., 2017). Also, establishing direct and continuous daily communication with consumers might be conducive to effectively show the true credible images. For example, dairy chain actors could use social media to regularly update the production process such as taking photos, publishing data, and responding to consumers' questions in a timely manner. When facing large food safety issues such as the melamine scandal, the actors who are responsible for the food crisis should acknowledge the fault in time and take responsibility. Timely communication with the public and provisioning of sufficient information are also crucial, including the effect of food risks, the way of identifying food risks, and measures to manage a crisis (Wilson et a., 2017). The dairy chain should also attach importance on establishing a unified and authoritative traceability system to make dairy actors' responsibility, production, and risk management visible to consumers; they should also inform consumers about the benefits of traceability systems to promote consumer use. To prevent participants from hiding information in the traceability system, detailed and uniform standards on traceable information should be formulated. At the same time, a strict audit mechanism should be established to ensure the authenticity of the provided information. Second, each dairy actor should formulate communication strategies focused on different aspects of trustworthiness. Farmers and manufacturers need to value more disclosure of the production process and advanced technology to get consumer recognition of their competence. Rated as the least trustworthy dairy actors, retailers should strictly control product quality during storage and sale and actively show their benevolence and care for consumers. As regulators, the government should take more proactive measures to prevent food scandals and strictly enforce regulations after food scandals to show their credibility to consumers. Third, given the effect of extensive media coverage on consumer perceptions of products and their risks (McCluskey et al., 2016) and the positive effects of online media and social media on consumer trust as indicated by this study, the dairy chain actors, especially the third parties, should use them effectively to increase the transparency of inspection information and build their authority and reputation. For example, the third parties should offer as much information as possible, so that such information could be reported by diverse media channels. They could also convey information to consumers by building their own websites or accounts on social media. Finally, given the existing heterogeneity in consumer trust, understanding who the target consumers are and how to best engage them and meet their needs is essential for each actor to develop their specific trust-building strategies. For example, retailers should use social media to strengthen young consumer trust, given that social media was found to be a major news source for young people (Hermida et al., 2012).

This study also shows some implications when studying consumer trust. First, consider the importance of consumer beliefs about trustworthiness, which are different among actors. Moreover, a more detailed clas- 
sification of trustworthiness is helpful to get insight into consumers' valuation and identification of determinants of trustworthiness in various actors. Second, the influence of different information channels should be included in the framework of consumer trust research. In addition to that, the researchers could examine the effects of online and offline information channels by classifying them as traditional media, online media, and social media. They should be aware that the 3 types of media could exert different effects on consumer trust in different actors. Third, when studying consumer trust, research should also pay special attention to the longterm effects of the major negative events.

This study proposes some recommendations for future work. First, the study areas in this research are either municipalities or provincial capitals, whose economies are above the national average. Although we included rural consumers in the samples, the overall education and income level of the respondents are relatively high. Therefore, the generalization of these results across China cannot be made. Furthermore, given the increasing trend in dairy consumption of rural households in China (He et al., 2016), the exploration of emerging rural markets, as well as the consumer trust there, could be of interest. Thus, more attention could be shifted to rural areas. Additionally, although consumer trust is determined by several internal and external factors, as investigated in this study, it is generally acknowledged that consumers' actual purchasing behavior is inconsistent with their stated attitude (e.g., Vermeir and Verbeke, 2006). From Drescher et al. (2012) and Muringai et al. (2017), it is known that consumer trust plays a role in food purchases and consumer preference and willingness to pay for credence food attributes, such as production methods. Therefore, it is essential to further explore whether, how, and to what extent consumer trust is embodied in their actual dairy-buying behavior. For example, it would be interesting to study how trust in food chain actors affects consumer preference and willingness to pay for food with quality certification provided by different actors. A thorough understanding of the mechanism between consumer psychology and behavior would help to better predict consumers' choices and make marketing strategies. Last, regarding the Likert scale design, offering an "I don't know" option in addition to the options with corresponding scores might be essential, so that respondents who are not able to provide a response would not be forced to choose an option, such as the midpoint (Chyung et al., 2017). This issue might also exist in this study. To avoid having respondents who do not understand the questions choose the midpoint, this study made some efforts to reduce such effect (e.g., improving the questionnaire by trail survey, providing careful interpretation to re- spondents during the survey). The future study should take this issue seriously and provide an "I don't know" option to avoid potential response bias.

In conclusion, Chinese consumers show a moderate level of trust in the Chinese dairy value chain. In comparison, the government and third parties receive relatively high trust levels compared with other actors such as farmers, processors and retailers. To maintain consumer trust, our results suggest that dairy supply actors should improve their competence in controlling dairy safety and show their benevolence to consumers, whereas the government and third parties need to focus on improving their credibility of supervision and openness of inspection information. The long-standing effect of the melamine scandal in 2008 on Chinese consumers calls the attention of all food value chain on effective of major food scandals. Diversified media channels should be used to help reduce the information asymmetry between consumers and the industry chain. Compared with traditional media, online and social media could be used to show production processes with photos, publish inspection data in a timely manner, and directly communicate with consumers to strengthen consumer trust. These results could help to formulate communication strategies at the industrial or public sector levels.

\section{ACKNOWLEDGMENTS}

This study was funded by a grant from the SinoDutch Dairy Development Centre of China Agricultural University (No. SDDDC2018R01). The authors have not stated any conflicts of interest.

\section{REFERENCES}

Afzal, H., M. A. Khan, L. Rehman, I. Ali, and S. Wajahat. 2010. Consumer's trust in the brand: Can it be built through brand reputation, brand competence and brand predictability. Int. Bus. Res. 3:43-51. https://doi.org/10.5539/ibr.v3n1p43.

Ariyawardana, A., K. Ganegodage, and M. Y. Mortlock. 2017. Consumers' trust in vegetable supply chain members and their behavioural responses: A study based in Queensland, Australia. Food Control 73:193-201. https://doi.org/10.1016/j.foodcont.2016.08 .006 .

Arnot, C., Y. Vizzier-Thaxton, and C. G. Scanes. 2016. Values, trust and science - building trust in today's food system in an era of radical transparency. Poult. Sci. 95:2219-2224. https://doi.org/10 $.3382 / \mathrm{ps} /$ pew168.

Cao, Y. 2019. Research on the formative mechanism of domestic infant milk powder safety trust. PhD Thesis. Department of Economics and Management, Northeast Agricultural University, China. (in Chinese)

Chen, W. 2013. The effects of different types of trust on consumer perceptions of food safety: An empirical study of consumers in Beijing Municipality, China. China Agric. Econ. Rev. 5:43-65. https://doi .org/10.1108/17561371311294757.

Chyung, S. Y., K. Roberts, I. Swanson, and A. Hankinson. 2017. Evidence-based survey design: The use of a midpoint on the Likert scale. Perform. Improv. 56:15-23. https://doi.org/10.1002/pfi .21727 . 
Coveney, J. 2008. Food and trust in Australia: Building a picture. Public Health Nutr. 11:237-245. https://doi.org/10.1017/ S1368980007000250.

Dairy Association of China and Ministry of Agriculture and Rural Affairs of China. 2018. Quality report of Chinese dairy industry. Accessed Sep. 25, 2020. https://www.sohu.com/a/249781647 -470064.

de Jonge, J., H. Van Trijp, R. Jan Renes, and L. Frewer. 2007. Understanding consumer confidence in the safety of food: Its twodimensional structure and determinants. Risk Anal. 27:729-740. https://doi.org/10.1111/j.1539-6924.2007.00917.x.

de Jonge, J., J. C. M. Van Trijp, I. A. Van der Lans, R. J. Renes, and L. J. Frewer. 2008. How trust in institutions and organizations builds general consumer confidence in the safety of food: A decomposition of effects. Appetite 51:311-317. https://doi.org/10 .1016/j.appet.2008.03.008.

Dolgopolova, I., R. Teuber, and V. Bruschi. 2015. Consumers' perceptions of functional foods: Trust and food-neophobia in a crosscultural context. Int. J. Consum. Stud. 39:708-715. https://doi .org/10.1111/ijcs.12184.

Drescher, L. S., J. de Jonge, E. Goddard, and T. Herzfeld. 2012. Consumer's stated trust in the food industry and meat purchases. Agric. Human Values 29:507-517. https://doi.org/10.1007/s10460 -012-9375-9.

Frewer, L. J., C. Howard, D. Hedderley, and R. Shepherd. 1998. Methodological approaches to assessing risk perceptions associated with food-related hazards. Risk Anal. 18:95-102. https://doi.org/10 .1111/j.1539-6924.1998.tb00919.x.

Gong, S., L. Bai, and J. Chen. 2012. Chinese consumer confidence in food safety based on the model of structural equation. Consum. Econ. 28:53-57. (in Chinese).

Grunert, K. G. 2002. Current issues in the understanding of consumer food choice. Trends Food Sci. Technol. 13:275-285. http://doi.org/ https://doi.org/10.1016/S0924-2244(02)00137-1.

He, Y., X. Yang, J. Xia, L. Zhao, and Y. Yang. 2016. Consumption of meat and dairy products in China: A review. Proc. Nutr. Soc. 75:385-391. https://doi.org/10.1017/S0029665116000641.

Henderson, J., J. Coveney, P. R. Ward, and A. W. Taylor. 2011. Farmers are the most trusted part of the Australian food chain: Results from a national survey of consumers. Aust. N. Z. J. Public Health 35:319-324. https://doi.org/10.1111/j.1753-6405.2011.00725.x.

Henderson, J., A. M. Wilson, S. B. Meyer, J. Coveney, M. Calnan, D. McCullum, S. Lloyd, and P. R. Ward. 2014. The role of the media in construction and presentation of food risks. Health Risk Soc. 16:615-630. https://doi.org/10.1080/13698575.2014.966806.

Henderson, J., A. M. Wilson, T. Webb, D. McCullum, S. B. Meyer, J. Coveney, and P. R. Ward. 2017. The role of social media in communication about food risks: Views of journalists, food regulators and the food industry. Br. Food J. 119:453-467. https://doi.org/ 10.1108/BFJ-07-2015-0272.

Hermida, A., F. Fletcher, D. Korell, and D. Logan. 2012. Share, like, recommend. Jpn. Stud. 13:815-824. https://doi.org/10.1080/ 1461670X.2012.664430

Houghton, J. R. G., G. Rowe, L. J. Frewer, E. Van Kleef, G. Chryssochoidis, O. Kehagia, S. Korzen-Bohr, J. Lassen, U. Pfenning, and A. Strada. 2008. The quality of food risk management in Europe: Perspectives and priorities. Food Policy 33:13-26. https://doi.org/ 10.1016/j.foodpol.2007.05.001

Jia, X., J. Huang, H. Luan, S. Rozelle, and J. Swinnen. 2012. China's milk scandal, government policy and production decisions of dairy farmers: The case of Greater Beijing. Food Policy 37:390-400. https://doi.org/10.1016/j.foodpol.2012.03.008.

Jiang, B. 2015. Study on consumers' trust repair under the perspective of crisis about dairy products quality and safety. PhD Thesis. Department of Economics and Management, Northeast Agricultural University, China. (in Chinese)

Jiang, Y., and A. Liu. 2016. Analysis on the influence factors of consumer's trust on certification label food: Based on 784 survey data. J. Hunan Agric. Univ. (Soc. Sci.). 17:034-040. (in Chinese) https: //doi.org/http://dx.doi.org/10.13331/j.cnki.jhau(ss).2016.01.006.
Kaplan, A. M., and M. Haenlein. 2010. Users of the world, unite! The challenges and opportunities of social media. Bus. Horiz. 53:59-68. https://doi.org/10.1016/j.bushor.2009.09.003.

Kollat, J., and F. Farache. 2017. Achieving consumer trust on Twitter via CSR communication. J. Consum. Mark. 34:505-514. https:// doi.org/10.1108/JCM-03-2017-2127.

Kuttschreuter, M., P. Rutsaert, F. Hilverda, Á. Regan, J. Barnett, and W. Verbeke. 2014. Seeking information about food-related risks: The contribution of social media. Food Qual. Prefer. 37:10-18. https://doi.org/10.1016/j.foodqual.2014.04.006.

Lassoued, R., and J. E. Hobbs. 2014. The determinants of consumer confidence in credence attributes: Trust in the food system and in brands. No. 166103 in 2014 AAEA/EAAE/CAES Joint Symposium: Social Networks, Social Media and the Economics of Food, Montreal, Canada. Agricultural and Applied Economics Association.

Lee, J. 2015. The double-edged sword: The effects of journalists' social media activities on audience perceptions of journalists and their news products. J. Comput. Mediat. Commun. 20:312-329. https:/ /doi.org/10.1111/jcc4.12113.

Li, C., and B. Jiang. 2015. Trust evaluation of dairy products quality safety in the perspective of situation and quality. Issues Agric. Econ. 36:75-82. (in Chinese) https://doi.org/10.13246/j.cnki.iae .2015.03.012.

Li, S., S. J. Sijtsema, M. Kornelis, Y. Liu, and S. Li. 2019a. Consumer confidence in the safety of milk and infant milk formula in China. J. Dairy Sci. 102:8807-8818. https://doi.org/10.3168/jds .2019-16638.

Li, S., C. Zhu, Q. Chen, and Y. Liu. 2019b. Consumer confidence and consumers' preferences for infant formulas in China. J. Integr. Agric. 18:1793-1803. https://doi.org/10.1016/S2095-3119(19)62589 $-\mathrm{X}$.

Liu, C., L. Han, and Y. Zhang. 2018. International comparison and development suggestions of China's dairy industry competitiveness. Chinese Rural Economy 2018:130-144 (in Chinese).

Liu, P., and L. Ma. 2016. Food scandals, media exposure, and citizens' safety concerns: A multilevel analysis across Chinese cities. Food Policy 63:102-111. https://doi.org/10.1016/j.foodpol.2016.07.005.

Lobb, A. 2005. Consumer trust, risk and food safety: A review. Acta Agric. Scand. Sect. C Food Econ. 2:3-12. https://doi.org/10.1080/ 16507540510033424.

Lu, F. 2010. The study of consumer trust on food safety after a significant food safety incident based on the investigation of Sanlu milk powder incident. MS Thesis. Department of Economics and Management, Huazhong Agricultural University, China. [in Chinese]

Lu, F., P. He, and R. Min. 2010. Analysis of factors influencing consumers trust on food safety. J. Northwest Agric. For. Univ. (Soc. Sci. Ed.) 10: 72-77. [in Chinese] https://doi.org/10.3969/j.issn .1009-9107.2010.01.015.

Macready, A. L., S. Hieke, M. Klimczuk-Kochańska, S. Szumiał, L. Vranken, and K. G. Grunert. 2020. Consumer trust in the food value chain and its impact on consumer confidence: A model for assessing consumer trust and evidence from a 5-country study in Europe. Food Policy 92:101880. https://doi.org/10.1016/j.foodpol .2020.101880.

McCluskey, J. J., N. Kalaitzandonakes, and J. Swinnen. 2016. Media coverage, public perceptions, and consumer behavior: Insights from new food technologies. Annu. Rev. Resour. Econ. 8:467-486. https://doi.org/10.1146/annurev-resource-100913-012630.

Mou, Y., and C. A. Lin. 2014. Communicating food safety via the social media: The role of knowledge and emotions on risk perception and prevention. Sci. Commun. 36:593-616. https://doi.org/10 $.1177 / 1075547014549480$.

Muringai, V., E. Goddard, H. Bruce, G. Plastow, and L. Ma. 2017. Trust and consumer preferences for pig production attributes in Canada. Can. J. Agric. Econ. 65:477-514. https://doi.org/10 $.1111 /$ cjag. 12138

National Bureau of Statistics. 2020. Statistical bulletin of national economic and social development of the People's Republic of China in 2019. Accessed Jan. 14, 2021. http://www.stats.gov.cn/tjsj/zxfb/ 202002/t20200228_1728913.html. 
Papadopoulos, A., J. M. Sargeant, S. E. Majowicz, B. Sheldrick, C. McKeen, J. Wilson, and C. E. Dewey. 2012. Enhancing public trust in the food safety regulatory system. Health Policy 107:98 103. https://doi.org/10.1016/j.healthpol.2012.05.010

Peng, Y., J. Li, H. Xia, S. Qi, and J. Li. 2015. The effects of food safety issues released by we media on consumers' awareness and purchasing behavior: A case study in China. Food Policy 51:44-52. https: //doi.org/10.1016/j.foodpol.2014.12.010.

Poortinga, W., and N. F. Pidgeon. 2003. Exploring the dimensionality of trust in risk regulation. Risk Anal. 23:961-972. https://doi.org/ 10.1111/1539-6924.00373.

Qiao, G., T. Guo, and K. K. Klein. 2012. Melamine and other food safety and health scares in China: Comparing households with and without young children. Food Control 26:378-386. https://doi .org/10.1016/j.foodcont.2012.01.045.

Qiu, H., J. Huang, C. Pray, and S. Rozelle. 2012. Consumers' trust in government and their attitudes towards genetically modified food: Empirical evidence from China. J. Chin. Econ. Bus. Stud. 10:67-87. https://doi.org/10.1080/14765284.2012.638471.

Ramaseshan, B., and A. Stein. 2014. Connecting the dots between brand experience and brand loyalty: The mediating role of brand personality and brand relationships. J. Brand Manag. 21:664-683. https://doi.org/10.1057/bm.2014.23.

Rousseau, D. M., S. B. Sitkin, R. S. Burt, and C. Camerer. 1998. Not so different after all: A cross-discipline view of trust. Acad. Manage. Rev. 23:393-404. https://doi.org/10.5465/amr.1998.926617.

Sapp, S. G., C. Arnot, J. Fallon, T. Fleck, D. Soorholtz, M. Sutton-Vermeulen, and J. J. H. Wilson. 2009. Consumer trust in the U.S. food system: An examination of the recreancy theorem. Rural Sociol. 74:525-545. https://doi.org/10.1111/j.1549-0831.2009 tb00703.x.

Shijiazhuang Municipal Bureau of Statistics. 2020. National Economic and Social Development Statistical Bulletin in 2019. Accessed Jan. 14, 2021. http://tjj.sjz.gov.cn/col/1584345215439/2020/04/13/ 1587111783229.html.

Shijiazhuang News Net. 2019. Our city achieve the breakthrough development of dairy industry. Accessed Jan. 12, 2021. http://www .sjz.gov.cn/col/1546231082146/2019/05/30/1559179126922.html.

Sina News. 2020. Hebei Dairy production output is No.1 in China for 6 consecutive years. Accessed Sep. 26, 2020. http://hebei.sina.com .cn/news/2020-05-15/detail-iirczymk1760823.shtml.

Sohu News. 2009. Review of the whole process of Sanlu melamine milk powder incident. Accessed Jan. 12, 2021. http://news.sohu.com/ 20090101/n261527309.shtml.

Sun, Q., and J. Wen. 2016. Consumers get ten times compensation due to purchasing expired milk. Accessed Sep. 25, 2020. https://www .chinacourt.org/article/detail/2016/08/id/2070901.shtml.

Sun, R. 2015. The research on evaluation of our consumer trust in dairy production enterprises. MS Thesis. Department of Management, Jilin University, China. [in Chinese]

Vermeir, I., and W. Verbeke. 2006. Sustainable food consumption: Exploring the consumer 'attitude-behavioral intention' gap. J. Agric. Environ. Ethics 19:169-194. https://doi.org/10.1007/s10806-005 $-5485-3$.

Wang, E. 2012. The study of consumers' response to food safety incident. PhD Thesis. Department of Economics and Management, Nanjing Agricultural University, China. [in Chinese]
Wang, Y., and L. Fan. 2013. Chinese consumer trust in food safety: Based on factor analysis and logit model. Seek 9:1-4 (in Chinese).

Wik, M., T. Aragie Kebede, O. Bergland, and S. T. Holden. 2004. On the measurement of risk aversion from experimental data. Appl. Econ. 36:2443-2451. https://doi.org/10.1080/0003684042000280580.

Wilson, A., S. B. Meyer, J. Coveney, J. Henderson, and P. R. Ward. 2014. Can Australian consumers trust the food supply? Nutridate $25: 2-4$.

Wilson, A. M., E. Withall, J. Coveney, S. B. Meyer, J. Henderson, D. McCullum, T. Webb, and P. R. Ward. 2017. A model for (re) building consumer trust in the food system. Health Promot. Int. 32:988-1000. https://doi.org/10.1093/heapro/daw024.

Winship, C., and R. D. Mare. 1984. Regression models with ordinal variables. Am. Sociol. Rev. 49:512-525. https://doi.org/10.2307/ 2095465

Wu, X., Y. Lu, H. Xu, M. Lv, D. Hu, Z. He, L. Liu, Z. Wang, and Y. Feng. 2018. Challenges to improve the safety of dairy products in China. Trends Food Sci. Technol. 76:6-14. https://doi.org/10 .1016/j.tifs.2018.03.019.

$\mathrm{Xu}$, J. 2020. Does the medium matter? A meta-analysis on using social media vs. traditional media in crisis communication. Public Relat. Rev. 46:101947. https://doi.org/10.1016/j.pubrev.2020.101947.

Xun, N. 2011. The evaluation research of consumer confidence in the safety of food based on the structural equation modelling. MS Thesis. Jilin University, China. [in Chinese

Yang, G. 2013. Contesting food safety in the Chinese media: Between hegemony and Counter-Hegemony. China Q. 214:337-355. https:/ /doi.org/10.1017/S0305741013000386.

Yee, W. M. S., R. M. W. Yeung, and J. Morris. 2005. Food safety: Building consumer trust in livestock farmers for potential purchase behaviour. Br. Food J. 107:841-854. https://doi.org/10.1108/ 00070700510629788.

Yu, H., H. H. Wang, and B. Li. 2018. Production system innovation to ensure raw milk safety in small holder economies: The case of dairy complex in China. Agric. Econ. 49:787-797. https://doi.org/ 10.1111/agec. 12460.

Zhang, J., X. Y. Yang, J. H. Mu, X. Li, Y. D. Li, and Y. H. Xiang. 2018. Analyze the current situation and problems of yogurt retail. China Dairy. 201:24-27. https://doi.org/10.16172/j.cnki.114768 2018.09.004.

Zhang, S. 2014. Muti-brand crisis impact on dairy industry trust. PhD Thesis. Department of Economics and Management, China Agricultural University, China. [in Chinese]

\section{ORCIDS}

Saiwei Li ๑ https://orcid.org/0000-0003-4653-2400

Yue Wang $\odot$ https://orcid.org/0000-0002-4279-9522

Yumei Liu @ https://orcid.org/0000-0002-2983-4258

Siet J. Sijtsema @ https://orcid.org/0000-0001-7599-559X 